\title{
Performance Analysis of Cascade Refrigeration System with alternate Refrigerants
}

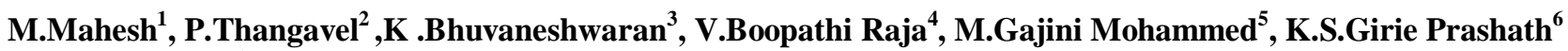 \\ ${ }^{1}$ Assistant Professor, Kongu Engineering College, India, mahesh25391@ gmail.com \\ ${ }^{2}$ Assistant Professor, Kongu Engineering College, India, ptvel@kongu.ac.in \\ ${ }^{3}$ B.E. Student, Kongu Engineering College, India, bhuvaneshkrish007@ gmail.com \\ ${ }^{4}$ B.E. Student, Kongu Engineering College, India, boopathirajavbr3599@ gmail.com \\ ${ }^{5}$ B.E. Student, Kongu Engineering College, India, gajinimohammed786@ gmail.com \\ ${ }^{6}$ B.E. Student, Kongu Engineering College, India, girieprashathmech@ gmail.com
}

\begin{abstract}
The cascade system containing Vapour compression refrigeration system (VCRS) and thermoelectric refrigeration system has been analyzed at different conditions of load and also with different refrigerants to come up with refrigerants that have low Global warming potential. The study was to identify the performance of this cascade system with alternate refrigerants such as R134a and Hydrocarbon mixtures (R290 and R600a) in a proportion of 50\% R290 and 50\%R600a. Readings for different loading conditions have been taken for identifying its capabilities. The results indicate that the Coefficient of performance was good in Hydrocarbon mixtures than that of R134a at loading conditions ant it could be a suitable replacement for the cascade refrigeration system.
\end{abstract}

Key words: cooling effect, condenser, load, performance, refrigerant,

\section{INTRODUCTION}

Cooling is a process, which removes the heat under controlled conditions from one place to another. Heat transport work generally run by mechanical work but can also be driven by electricity, magnetism, elasticity, laser or other means. Refrigeration is a science which produces and maintains heat below the surrounding temperature. This requires refrigerating warm material. The heat still flows down to lower temperature from the higher temperature. Heat is a big issue that needs to be reduced wherever possible. In such cases, the refrigeration unit shall be used.

Vapor Compression Cooling System (VCRS) is normally used for cooling the substance. There are four thermodynamic processes at VCRS, namely

- Compression

- Condensation

- Expansion

- Evaporation
From the evaporator low temperature and low pressure coolant emerges and join the compressor. The coolant is squeezed in such a way that the refrigerant temperature is increased. The high temperature and high pressure refrigerant vapour joins the condenser. Temperature decreases at constant pressure during the condensation process. The expansion valve joins high pressure and low temperature liquid refrigerant, and the pressure decrease in the expansion valve occurs. Eventually, liquid refrigerant, low temperature and pressure, exits the evaporator. At constant pressure cycle, it holds heat from the evaporator.

VCRS is an improved version[1],[2] of an air cooling device in which an efficient working element, called a coolant, is used. VCRS is now a day used for all refrigeration purposes. Heat was absorbed and removed from the refrigerating room and then dismisses it where VCRS uses a circulating liquid refrigerant as a medium. The standard VCRS comes with four main components

\section{- Compressor \\ - Condenser \\ - Expansion Valve \\ - Evaporator}

VCRS works based on the Reverse Carnot cycle and systems that consume electricity. In the following components of the VCRS, the refrigerant changes its process.

Peltier found that there was an opposite phenomenon to the Seebeck Effect by which thermal energy could be absorbed at one dissimilar junction of metal and discharged at the other junction as electrical current flows inside the circuit is closed.

Canan Cimsit, Ilhan Tekin Ozturk [3] investigates about compression absorption cascade refrigeration cycles. Theoretically these cycles were analyzed and compared in the compression and absorption sections by using different refrigerants. $\mathrm{LiBr}-\mathrm{H}_{2} \mathrm{O}$ and $\mathrm{NH}_{3}-\mathrm{H}_{2} \mathrm{O}$ are used as fluid pair in the section of cascade absorption, where as R134a, R-410A and $\mathrm{NH}_{3}$ fluids [4] were used in the section of cascade process vapour compression. Separately the results show that the thermal energy consumption of the cascade refrigeration cycle 
could be reduced by $35 \%$ by using the $\mathrm{LiBr}-\mathrm{H}_{2} \mathrm{O}$ pair for the absorption portion and also the general efficiency coefficient (COP cyclegen) could be improved by $33 \%$ compared to the $\mathrm{NH}_{3}-\mathrm{H}_{2} \mathrm{O}$ pair.

P. Thangavel [5] et al. discussed the Simulation analysis of Compression Refrigeration Cycle with different Refrigerants. Hydrocarbon refrigerants such as R290 and R600a are known as refrigerants in a compression cooling system by mixing them at various mass fractions around $20 \%+80 \%, 25 \%+$ $75 \%, 50 \%+50 \%$ and $75 \%+25 \%$ respectively. Among the hydrocarbon refrigerants group, The R290 and R600a[6] mixture has optimal performance in higher refrigeration effect, better heat transfer and COP at a concentration of $50 \%$ each.

Kun Liang, Zhaohua Li, Ming Chen [7] deals with Comparisons between heat pipe, thermoelectric system, and vapour compression refrigeration system for electronics cooling. This paper examined three comparable electronic cooling systems, like heat pipe (passive system), thermoelectric and vapor compression refrigeration systems. The VCR system's cooling power and COP is much superior to any thermoelectric device.

D. Astrain, J.G. Viaan [8] dealt with Increase of COP by maximizing heat dissipation in thermoelectric refrigeration. A heat dissipation system is given from the hot side of Peltier pellets in thermoelectric cooling, based on the principle of a phase-changing thermosyphon. Analytical calculations accomplish device construction based on a semi-empirical model and computational fluid dynamics simulations. With the construction of two prototypes of domestic thermoelectric refrigerators, one with developed system and the other with fins dissipator. Experimentally it could be proved that the use of phase-changing thermosyphons raises the output coefficient to $32 \%$.

Yanxing Zhao,[9] et al. dealt with Azeotropic refrigerants and its application in vapour compression refrigeration cycle. Because of their unique thermophysical properties the azeotropic refrigerants attract growing attention. A mixedrefrigerant evaluation is carried out on the VCRS and regenerative cycle, synthetically taking into account the coefficient of performance, volumetric refrigeration cooling, pressure ratio and discharge temperature. The tests show that all the positive azeotropic coolants have achieved a better VRC than their formulations. Positive azeotropes (especially ammonia-based azeotropes) are found to perform better in coefficient of performance, volumetric refrigeration capacity, discharge temperature and pressure ratio, due to the high pressure at the azeotropic position and the resulting extreme density[10],[11]

The use of R134a is best for VCRS system compared to all cases of a refrigerant study. Using a cascade refrigeration system combination of Thermoelectric module with any other refrigeration system increases the coefficient of performance. COP and exergetic efficiency are maximum for R507A in compared with R404A at condenser temperatures between 40 ${ }^{\circ} \mathrm{C}$ and $55^{\circ} \mathrm{C}$. For all cascade cycles cases, using $\mathrm{LiBr}-\mathrm{H}_{2} \mathrm{O}$ fluid pair in the absorption segment may gives the highest output coefficient as opposed to the $\mathrm{NH}_{3}-\mathrm{H}_{2} \mathrm{O}$ fluid pair. Hydrocarbon mixtures with a proportion of 50:50 give a higher coefficient of performance compared to R134a. GWP and ODP are higher in conventional refrigerants so alternative refrigerants like Hydrocarbon refrigerants with low GWP are used to improve COP as well. Cascade refrigeration system gives the best coefficient of performance than VCRS[12],[13],[14],[15].

\section{EXPERIMENTAL ARRANGEMENT}

\subsection{Experimental Setup}

The experimental setup incorporates both the vapour compression refrigeration system (VCRS) and a thermoelectric refrigeration system. The thermoelectric refrigerator setup is a refrigerator that is used in vehicles as a mini-refrigerator for small scale cooling. The VCRS system that has components namely compressor, condenser, expansion valve and evaporator were assembled to work like a refrigerator. These two refrigeration systems were combined using the copper tubes which have good thermal conductivity. Fig 1 shows the thermoelectric refrigerator which is made up of a plastic material. It is a portable car refrigerator which keeps things cooler and warmer. The thermoelectric refrigerator needs a $49 \mathrm{~W}$ power to run and has a capacity of cooling up to 4 litres of a load. The maximum cooling temperature is limited to $277.15 \mathrm{~K}$.

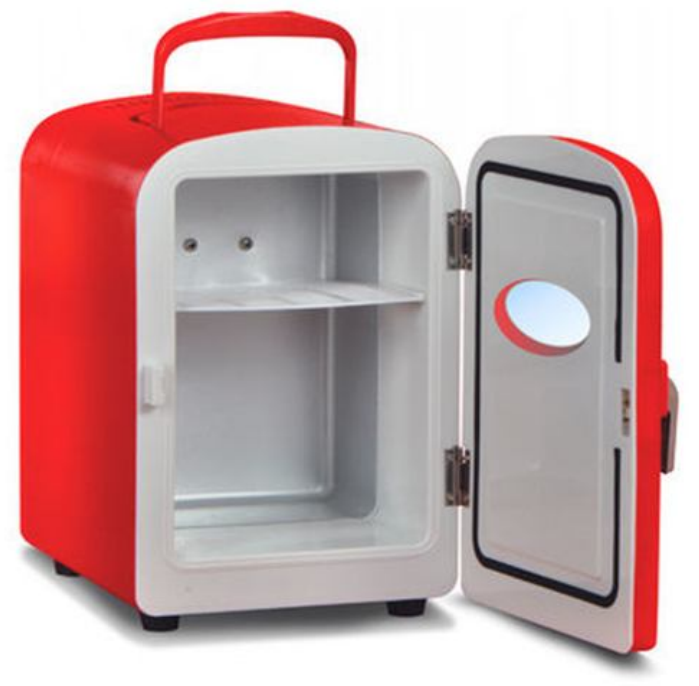

Figure 1: Portable Thermoelectric refrigerator

\subsection{Fabrication of Cascade Refrigeration System}

Figure 2 shows the cascade refrigerator setup which has both refrigeration systems. The refrigerator has a common evaporator so that it has a cooling capacity up to 15 litres. The evaporator is made up of thermocol box which acts as an insulating box for isolating it from the atmospheric temperature. The compressor that can run at a speed of $1600 \mathrm{rpm}$ for effective cooling purpose. The condenser is connected at the outlet of the compressor then it is connected to the thermoelectric refrigerator and then to the evaporator. At the compressor inlet and outlet two pressure gauges were placed. Temperature indicators with a thermocouple were 
placed at compressor's inlet and outlet, condenser outlet and evaporator tube. These thermocouples are placed to observe the temperature change based on various loading conditions for different time intervals.

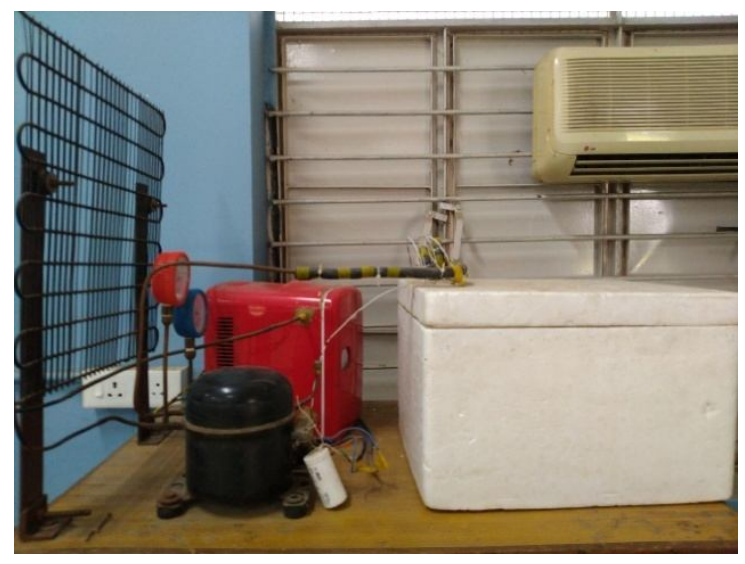

Figure 2: Cascade refrigeration setup

\subsection{Formula Used}

Vapour compression cooling (VCRS) output is measured with and without a thermoelectric module. For tests, different loads such as no-load, 2 litres, 4 litres and 6 litres were used. The numerous observations such as refrigeration effect, condenser heat rejection rate, compressor function and $\mathrm{COP}$ are considered for with and without TEM to find the performance improvement of VCRS.

\section{$\mathrm{P}_{1}$ - Suction pressure (bar)}

$\mathrm{P}_{2}$ - Delivery pressure (bar)

$\mathrm{T}_{1}$-Temperature of refrigerant at compressor inlet $\left({ }^{\circ} \mathrm{C}\right)$

$\mathrm{T}_{2}$-Temperature of refrigerant at compressor outlet $\left({ }^{\circ} \mathrm{C}\right)$

$\mathrm{T}_{3}$-Temperature of refrigerant at condenser outlet $\left({ }^{\circ} \mathrm{C}\right)$

$\mathrm{T}_{4}$-Temperature of refrigerant at expansion valve outlet $\left({ }^{\circ} \mathrm{C}\right)$

Enthalpy at the compressor inlet

Enthalpy at the compressor outlet

$$
\mathrm{h}_{1}=\mathrm{h}_{\mathrm{g}}+\mathrm{C}_{\mathrm{pv}}\left(\mathrm{T}_{\text {sup }}-\mathrm{T}_{\text {sat }}\right)
$$

Enthalpy at the condenser outlet

$$
\mathrm{h}_{2}=\mathrm{h}_{\mathrm{g}}+\mathrm{C}_{\mathrm{pv}}\left(\mathrm{T}_{\text {sup }}-\mathrm{T}_{\text {sat }}\right)
$$

$$
\mathrm{h}_{3}=\mathrm{h}_{\mathrm{f}}-\mathrm{C}_{\mathrm{pl}}\left(\mathrm{T}_{\mathrm{sat}}-\mathrm{T}_{3}\right)
$$

\section{DISCUSSIONS}

VCRS is operated under no load with and without TEM. So the condensation effect, refrigeration effect, compressor work and COP of the VCRS have been obtained and comparison is given below.

\subsection{Performance Improvement analysis of VCRS in R134a Under No Load}

VCRS is operated under no load with and without TEM. So the condensation effect, refrigeration effect, compressor work and COP of the VCRS have been obtained and comparison is given below.

\subsubsection{Comparison of COP}

Figure 3 shows the COP of VCRS with and without TEM. COP obtained in the VCRS without TEM is 6.11 and with TEM is 6.29 for the no-load condition. It is observed that the COP of VCRS with TEM is increased by about $2.94 \%$ than the COP without TEM process.

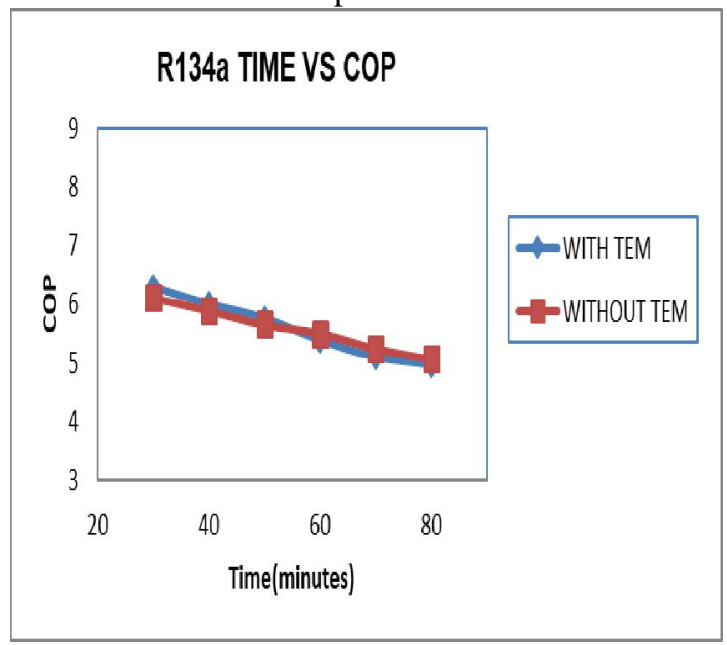

Figure 3: Time vs COP

\subsubsection{Comparison of Compressor Work}

Figure 4 shows the compressor work of VCRS with and without TEM. Compressor work is obtained in the VCRS without TEM is $27.576 \mathrm{~kJ} / \mathrm{kg}$ and with TEM is $27.25 \mathrm{~kJ} / \mathrm{kg}$ for the no-load condition. It is observed that the compressor work of VCRS with TEM is decreased by $1.176 \%$ than the compressor without the TEM process.

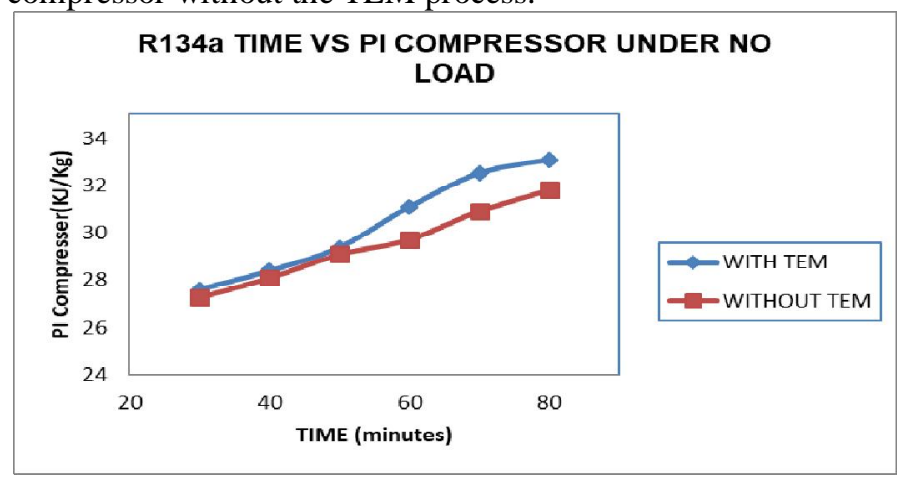

Figure 4: Time vs PI compressor 3.2 Performance Improvement analysis of VCRS in R134a under 6 Litre Load

VCRS is operated under 6 litre with and without TEM. So the condensation effect, refrigeration effect, compressor work and COP of the VCRS have been obtained and comparisons are given below. 


\subsubsection{Comparison of COP}

Figure 5 shows the COP of VCRS with and without TEM. COP obtained in the VCRS without TEM is 7.49 and with TEM is 11.22 for 6 litre load condition. It is observed that the COP of VCRS with TEM is increased by about $33.2 \%$ than the COP without TEM process.

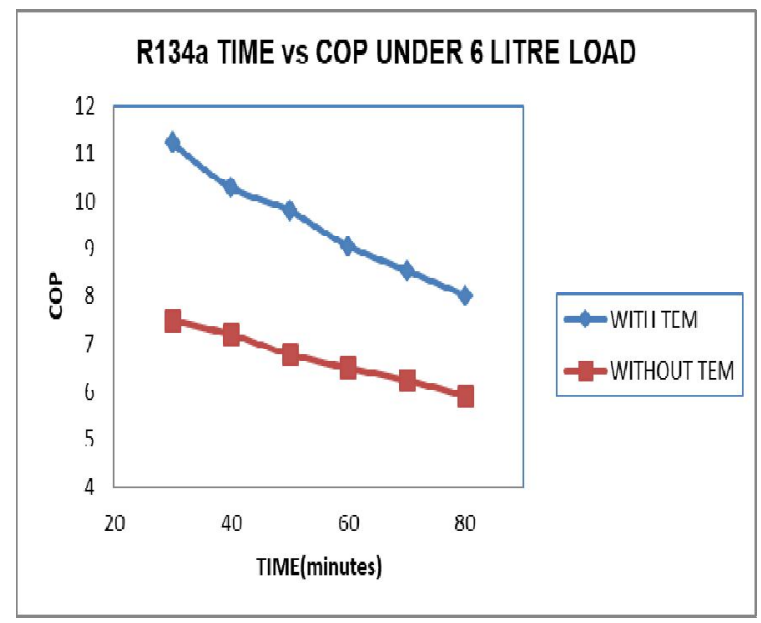

Figure 5: Time vs COP

\subsubsection{Comparison of Compressor Work}

Figure 6 shows the compressor work of VCRS with and without TEM. Compressor work is obtained in the VCRS without TEM is $22.17 \mathrm{~kJ} / \mathrm{kg}$ and with TEM is $15.30 \mathrm{~kJ} / \mathrm{kg}$ for 6 litre load condition. It is observed that the compressor work of VCRS with TEM is decreased by about $30.98 \%$ than the compressor without the TEM process.

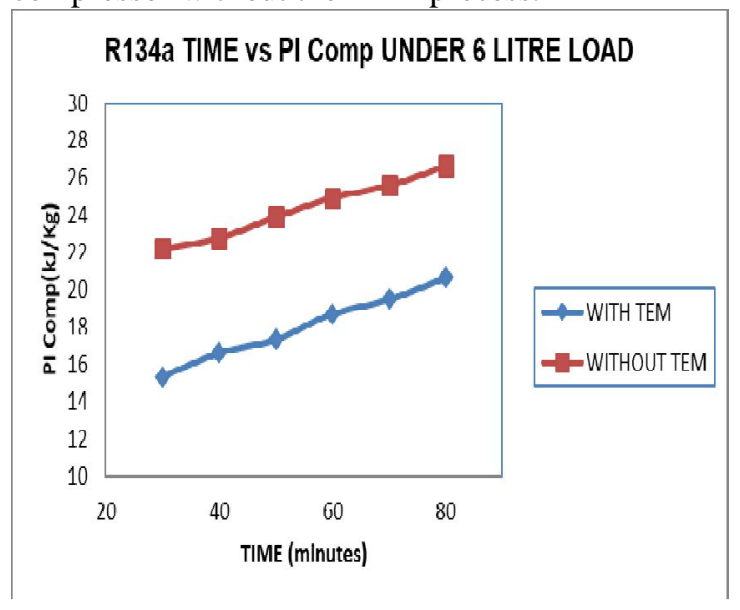

Figure 6: Time vs PI compressor

3.3 Performance Improvement analysis of VCRS in a Mixture of R290 (50\%) and R600a (50\%) Under No Load

VCRS is operated under no load with and without TEM. So the condensation effect, refrigeration effect, compressor work and COP of the VCRS have been obtained and comparison is given below.

\subsubsection{Comparison of COP}

Figure 7 shows the COP of VCRS with and without TEM. COP obtained in the VCRS without TEM is 4.46 and with TEM is 5.14 for the no-load condition. It is observed that the COP of VCRS with TEM is increased by about $15.24 \%$ than the COP without TEM process.

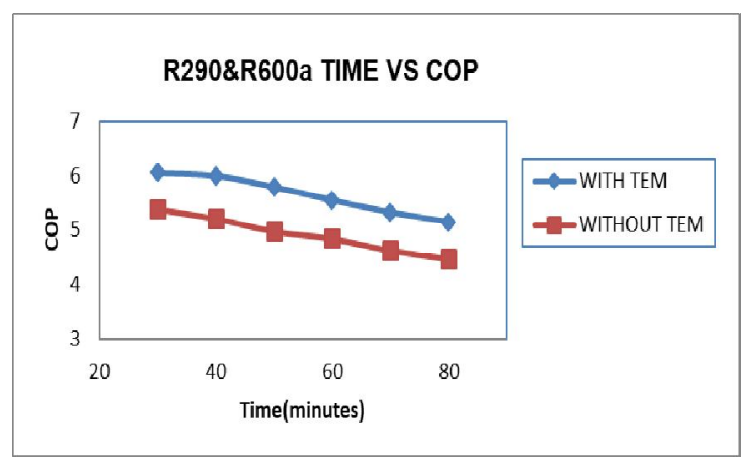

Figure 7: Time vs COP

\subsubsection{Comparison of Compressor Work}

Figure 8 shows the compressor work of VCRS with and without TEM. Compressor work is obtained in the VCRS without TEM is $62.05 \mathrm{~kJ} / \mathrm{kg}$ and with TEM is $68.44 \mathrm{~kJ} / \mathrm{kg}$ for the no-load condition. It is observed that the compressor work of VCRS with TEM is decreased by about $9.33 \%$ than the compressor without the TEM process.

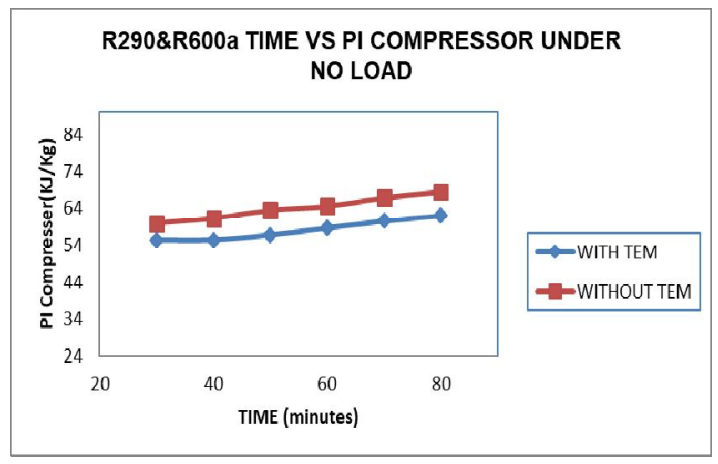

Figure 8: Time vs PI Compressor

\subsection{Performance Improvement analysis of VCRS in a} Mixture of R290 (50\%) and R600a (50\%) Under 6 Litre Load

VCRS is operated under 6 litres with and without TEM. So the condensation effect, refrigeration effect, compressor work and COP of the VCRS have been obtained and comparisons are given below.

\subsubsection{Comparison of COP}

Figure 9 shows the COP of VCRS with and without TEM. COP obtained in the VCRS without TEM is 6.21 and with 
TEM is 5.85 for 6-litre load condition. It is observed that the COP of VCRS with TEM is increased by about $6.15 \%$ than the COP without TEM process.

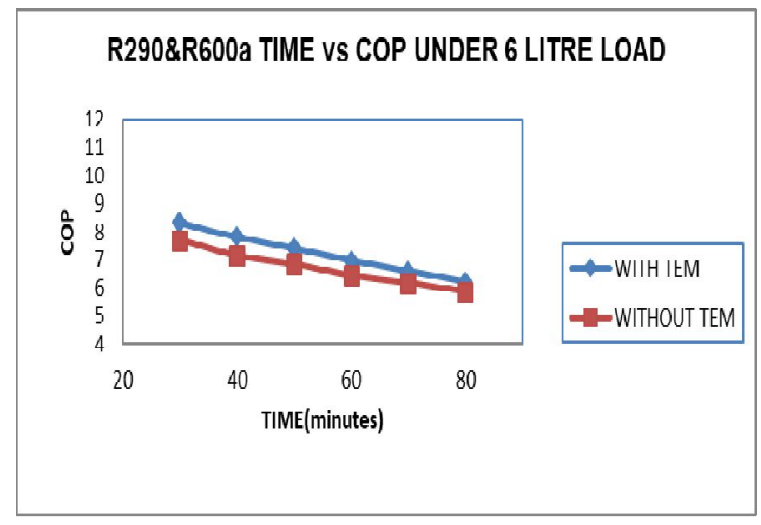

Figure 9: Time vs COP

\subsubsection{Comparison of Compressor Work}

Figure 10 shows the compressor work of VCRS with and without TEM. Compressor work is obtained in the VCRS without TEM is $53.95 \mathrm{~kJ} / \mathrm{kg}$ and with TEM is $54.22 \mathrm{~kJ} / \mathrm{kg}$ for 6-litre load condition. It is observed that the compressor work of VCRS with TEM is decreased by about $0.5 \%$ than the compressor without the TEM process.

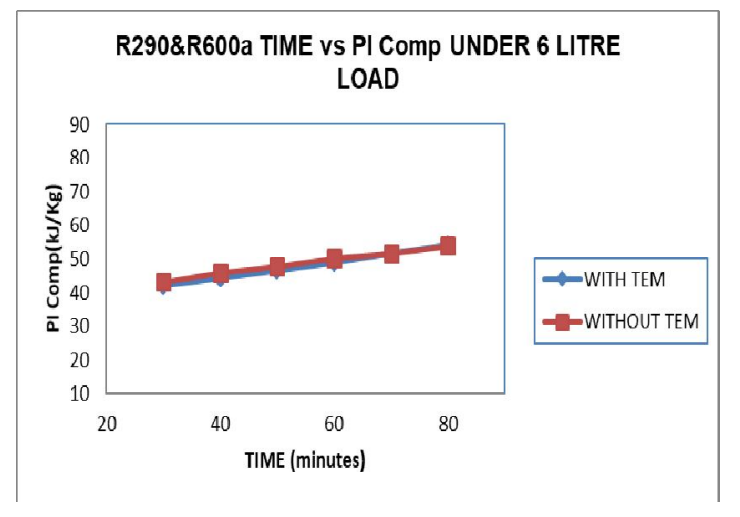

Figure 10: Time vs PI Compressor

\section{RESULTS}

The refrigeration effect, condenser function, and refrigerator COP are improved with TEM when compared to TEM-free refrigerator. Input from compressor work in the TEM refrigerator has decreased. The improvements are provided for the maximum load (6 litres) by considering the different loads in the evaporator.

\subsection{Performance Improvement Analysis of VCRS without} TEM of Refrigerants R134a and Hydrocarbon Mixtures of R290 (50\%) and R600a (50\%) Under 6 Litre Load

VCRS is operated under 6 litre without TEM. So the condensation effect, refrigeration effect, compressor work and
COP of the VCRS have been obtained and comparisons are given below.

\subsubsection{Comparison of COP}

Figure 11 shows the COP of VCRS without TEM refrigerants R134a and Hydrocarbon mixtures. COP obtained in R134a is 5.91 and Hydrocarbon mixture is 5.85 for 6-litre load condition. It is observed that the COP of VCRS with R134a is increased by about $1.07 \%$ than the COP of Hydrocarbon mixtures.

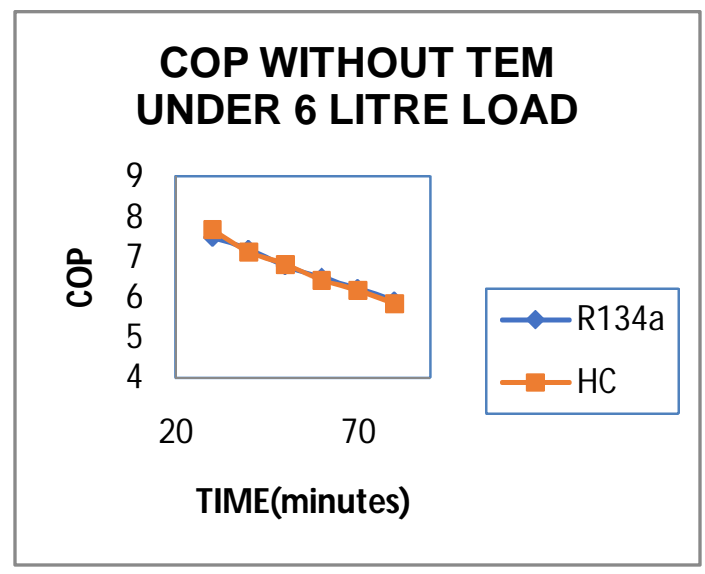

Figure 11: Time vs COP

\subsubsection{Comparison of Refrigeration Effect}

Figure 12 shows the Refrigeration effect of VCRS without TEM refrigerants R134a and Hydrocarbon mixtures. Refrigeration effect obtained in R134a is $166.16 \mathrm{KJ} / \mathrm{kg}$ and Hydrocarbon mixture is 331.54 for 6-litre load condition. It is observed that the Refrigeration effect of VCRS with R134a is decreased by about $99.52 \%$ than the Refrigeration effect of Hydrocarbon mixtures.

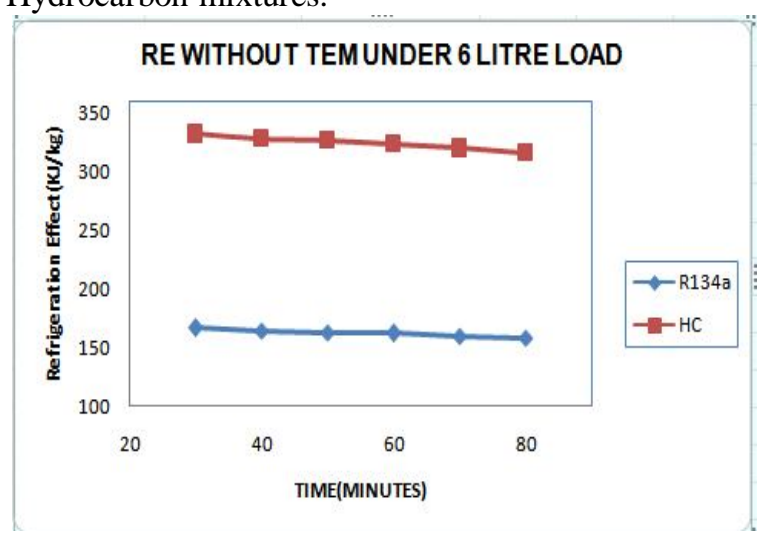

Figure 12: Time vs RE

\subsubsection{Comparison of Condenser Effect}

Figure 13 shows the Condenser effect of VCRS without TEM refrigerants R134a and Hydrocarbon mixtures. Condenser effect obtained in R134a is $188.34 \mathrm{KJ} / \mathrm{kg}$ and Hydrocarbon mixture is $374.599 \mathrm{KJ} / \mathrm{kg}$ for 6-litre load condition. It is 
observed that the Condenser effect of VCRS with R134a is increased by about $98.89 \%$ than the Condenser effect of Hydrocarbon mixtures.

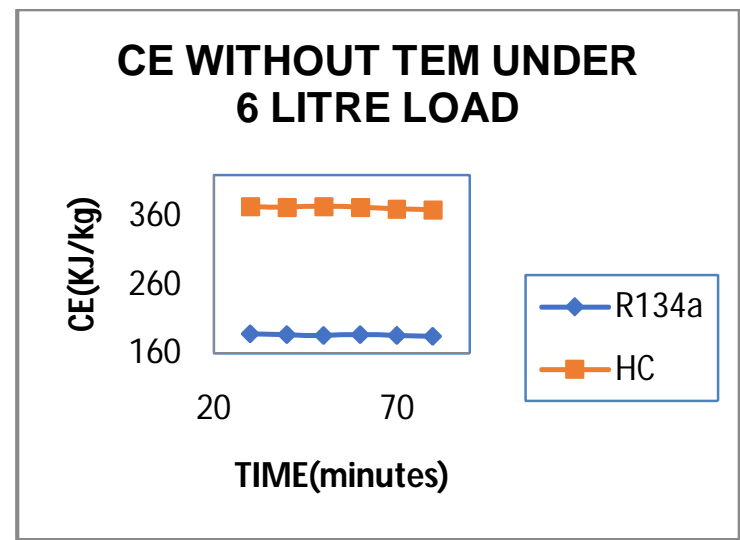

Figure 13: Time vs CE

\subsubsection{Comparison of Compressor Work}

Figure 14 shows the Compressor work of VCRS without TEM refrigerants R134a and Hydrocarbon mixtures. Compressor work obtained in R134a is $22.17 \mathrm{KJ} / \mathrm{kg}$ and Hydrocarbon mixture is $43.06 \mathrm{KJ} / \mathrm{kg}$ for 6-litre load condition. It is observed that the Compressor work of VCRS with R134a is increased by about $94.22 \% \%$ than the Compressor work of Hydrocarbon mixtures.

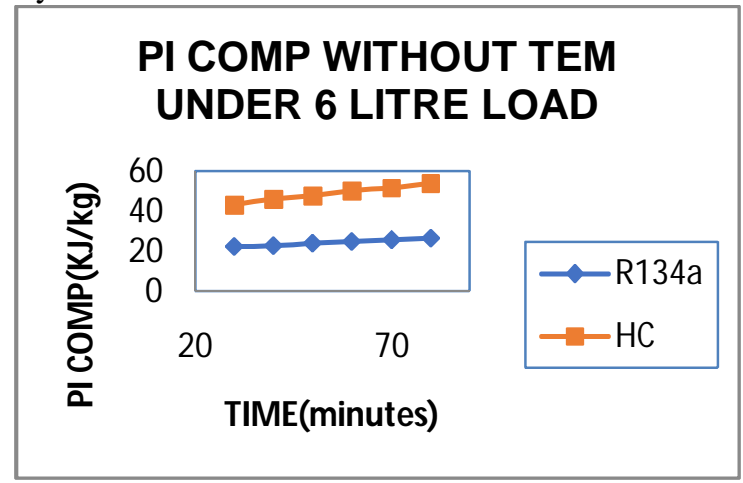

Figure 14: Time vs PI compressor

4.2 Performance Improvement analysis of VCRS with TEM of Refigerants R134a and Hydrocarbon Mixtures of R290 (50\%) and R600a (50\%) Under 6litre Load

VCRS is operated under 6 litre with TEM. So the condensation effect, refrigeration effect, compressor work and COP of the VCRS have been obtained and comparisons are given below.

\subsubsection{Comparison of COP}

Figure 15 shows the COP of VCRS with TEM refrigerants R134a and Hydrocarbon mixtures. COP obtained in R134a is 11.22 and Hydrocarbon mixture is 8.33 for 6-litre load condition. It is observed that the COP of VCRS with R134a is increased by about $25.75 \%$ than the COP of Hydrocarbon mixtures.

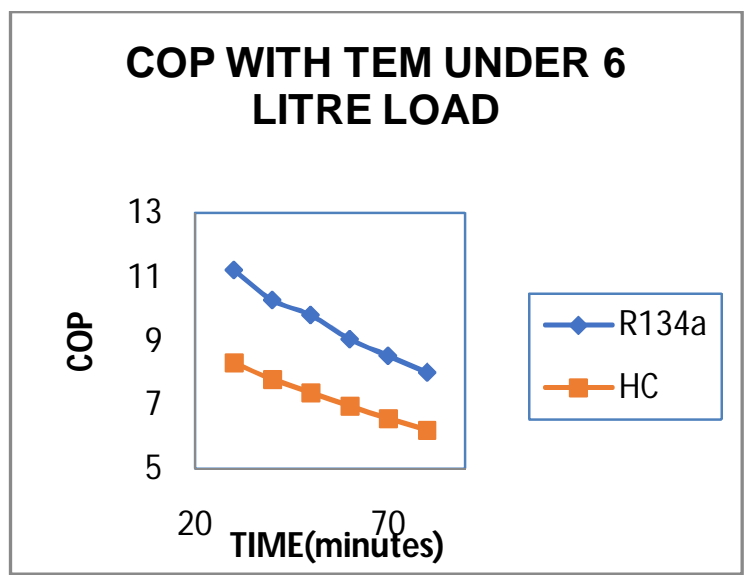

Figure 15: Time vs COP

\subsubsection{Comparison of Refrigeration Effect}

Figure 16 shows the Refrigeration effect of VCRS with TEM refrigerants R134a and Hydrocarbon mixtures. Refrigeration effect obtained in R134a is $171.78 \mathrm{KJ} / \mathrm{kg}$ and Hydrocarbon mixture is $349.87 \mathrm{KJ} / \mathrm{kg}$ for 6-litre load condition. It is observed that the Refrigeration effect of VCRS with R134a is decreased by about $101.53 \%$ than the Refrigeration effect of Hydrocarbon mixtures.

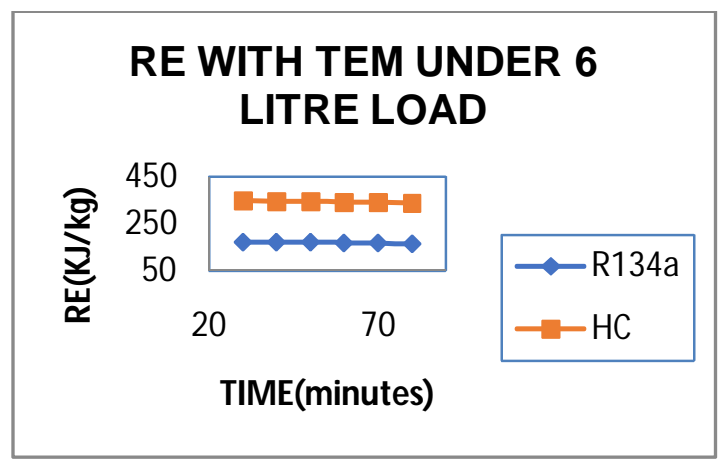

Figure 16. Time vs RE

\subsubsection{Comparison of Condenser Effect}

Figure 17 shows the Condenser effect of VCRS with TEM refrigerants R134a and Hydrocarbon mixtures. Condenser effect obtained in R134a is $187.09 \mathrm{KJ} / \mathrm{kg}$ and Hydrocarbon mixture is $391.85 \mathrm{KJ} / \mathrm{kg}$ for 6-litre load condition. It is observed that the Condenser effect of VCRS with R134a is increased by about $94.75 \%$ than the Condenser effect of Hydrocarbon mixtures. 


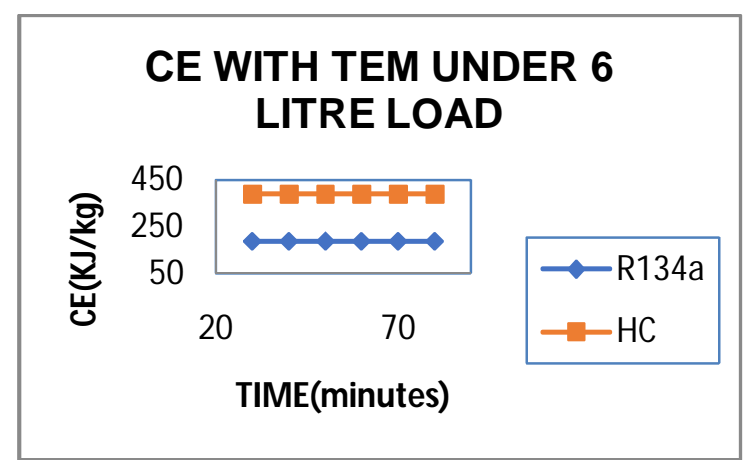

Figure 17: Time vs CE

\subsubsection{Comparison of Compressor Work}

Figure 18 shows the Compressor work of VCRS with TEM refrigerants R134a and Hydrocarbon mixtures. Compressor work obtained in R134a is $15.3 \mathrm{KJ} / \mathrm{kg}$ and Hydrocarbon mixture is $41.97 \mathrm{KJ} / \mathrm{kg}$ for 6 -litre load condition. It is observed that the Compressor work of VCRS with R134a is increased by about 52.12 than the Compressor work of Hydrocarbon mixtures.

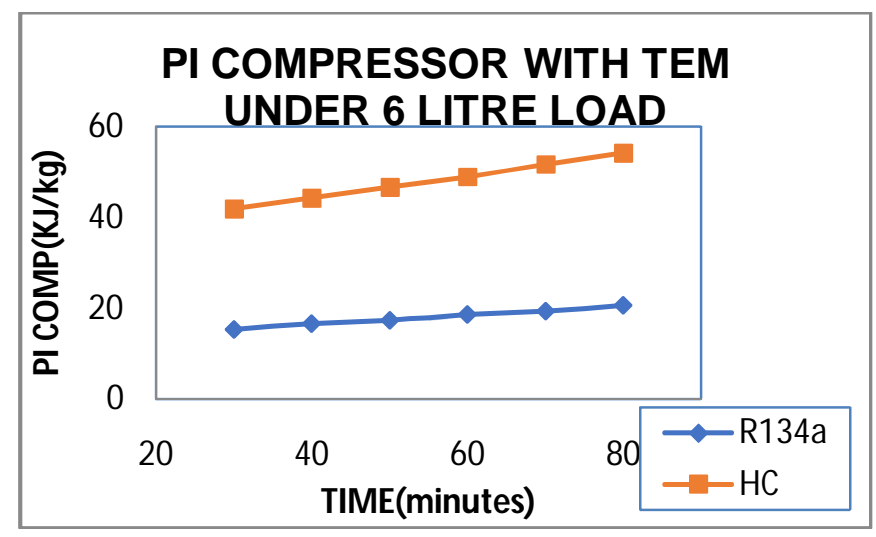

Figure 18: Time vs PI Compressor

\section{CONCLUSION}

- By using the thermoelectric module Refrigeration effect for R134a and mixture of R290(50\%) and R600a(50\%) is increased by $3.38 \%$ and $6.33 \%$ respectively.

- Condenser effect for R134a and a mixture of R290(50\%) and $\mathrm{R} 600 \mathrm{a}(50 \%)$ is increased by $1.09 \%$ and $5.85 \%$ respectively by using the thermoelectric module.

- Compressor work for R134a refrigerant and mixture of $\mathrm{R} 290(50 \%)$ and $\mathrm{R} 600 \mathrm{a}(50 \%)$ is decreased by $30.98 \%$ and $0.5 \%$ respectively by using a thermoelectric module.

- COP for R134a refrigerant and mixture of R290(50\%) and $\mathrm{R} 600 \mathrm{a}(50 \%)$ is increased by $33.2 \%$ and $6.15 \%$ respectively by using the thermoelectric module.

- Replacing R134a by and hydrocarbon mixture (R290 and R600a) the COP for with TEM and without TEM has decreased about $25.75 \%$ and $1.07 \%$.
- Replacing R134a by hydrocarbon mixture (R290 and R600a) the refrigeration effect for with TEM and without TEM has increased about $101.53 \%$ and $99.52 \%$.

- Replacing R134a by hydrocarbon mixture (R290 and R600a) the condenser effect for with TEM and without TEM has increased by about $94.75 \%$ and $98.89 \%$.

- Replacing R134a by hydrocarbon mixture (R290 and R600a) the power input to Compressor has increased by about $52.12 \%$ and $94.22 \%$.

- The Global Warming Potential was reduced from 1300 to 20 by using hydrocarbon refrigerant R290 and R600a in a proportion of 50:50.

- From the above conclusions, the performance of the refrigerator can be improved by using a thermoelectric module when compared to the normal domestic refrigerator without thermoelectric module.

\section{ACKNOWLEDGEMENT}

This work was supported by Kongu Engineering College, Perundurai, Erode.

\section{REFERENCES}

1. Satha Aphornratana, Thanarath Sriveerakul, Analysis of a combined Rankine-vapour-compression refrigeration cycle, Energy Conversion and Management, vol 51, pp 2557-2564, 2010.

2. Akhilesh Arora, S.C. Kaushik, Theoretical analysis of a vapour compression refrigeration system with $\mathrm{R502}$, R404A and R507A, International journal of refrigeration, vol 31, pp 998-1005, (2008)

3. Canan Cimsit a, Ilhan Tekin Ozturk, Analysis of compression absorption cascade refrigeration cycles, Applied Thermal Engineering, vol 40, Pages 311-317, 2008

4. Jincan Chen, Chih wu, Optimization of two-stage combined refrigeration system, energy conversion management, vol 37, pp 353-358, 1996

5. P.Thangavel, Dr.P.Somasundaram, T.Sivakumar, C.Selva Kumar, G.Vetriselvan, Simulation Analysis of Compression Refrigeration Cycle with Different Refrigerants, International Journal of Engineering and Innovative Technology (IJEIT), Vol 2, Issue 10, April 2013

6. Sachin Kaushik, Dr.S.Singh, Thermodynamic Analysis of Vapor Absorption Refrigeration System and Calculation of COP, international journal for research in applied science and engineering technology, Vol. 2 Issue II, February 2014

7. Kun Liang, Zhaohua Li, Ming Chen, Comparisons between heat pipe, thermoelectric system, and vapour compression refrigeration system for electronics cooling, Applied Thermal Engineering , Vol 146, pp 260267,2019 
8. D. Astrain, J.G. Viaan, M. Domınguez, Increase of COP in the thermoelectric refrigeration by the optimization of heat dissipation, Applied Thermal Engineering , Vol 23, pp 2183-2200,2019

9. Yanxing Zhao, Zhibin Li, Xiaojun Zhang, Xian Wang, Xueqiang Dong, Bo Gao, Maoqiong Gonga, Jun Shen, Azeotropic refrigerants and its application in vapour compression refrigeration cycle, International Journal of Refrigeration, Vol 108, pp 1-13,2019

10. Jameel-Ur-Rehman Khan And Syed M. Zubai, Design and rating of a two-stage vapour compression Refrigeration system, Elsevier Science Ltd, Vol 23, pp. 867-878, 1998.

11. Vaibhav Jain, Gulshan Sachdeva, S.S. Kachhwaha, Comparative performance study and advanced exergy analysis of novel vapor compression-absorption integrated refrigeration system, Energy Conversion and Management, Vol 172, pp 81-97, 2018

12. Vaibhav Jain, Gulshan Sachdeva, Surendra Singh Kachhwaha, Thermo-economic and environmental analyses based multi-objective optimization of vapor compression-absorption cascaded refrigeration system using NSGA-II technique, Energy Conversion and Management, Vol 113, pp 230-242,2016

13. Santiphap Nakkaew, Thunyawat Chitipalungsri, Ho Seon Ahn, Application of the heat pipe to enhance the performance of the vapor compression refrigeration system, Case Studies in Thermal Engineering, Volume 15, Page 100531,2019

14. Eko Julianto, Waluyo adi siswanto,Marwan Effandy Characteristics of Temperature changes and Stress of Float Glass under Heat Radiation, International Journal of Emerging Trends in Engineering Research, vol 7 no:9, pp 228-233,2019

15. Sergey Mikhailovich Usikov, Simulation of Heat Transfer by Water Heating Convectors, International Journal of Emerging Trends in Engineering Research, vol 8 no 3, pp 726-734,2020 